\title{
Sage Simulation Model for Technology Demonstration Convertor by a Step-by-Step Approach
}

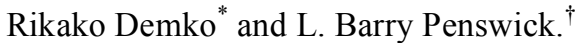 \\ Sest, Inc., Middleburg Heights, Ohio 44130
}

\begin{abstract}
The development of a Stirling model using the 1-D Sage design code was completed using a step-by-step approach. This is a method of gradually increasing the complexity of the Sage model while observing the energy balance and energy losses at each step of the development. This step-by-step model development and energy-flow analysis can clarify where the losses occur, their impact, and suggest possible opportunities for design improvement. Starting with the simplest Technology Demonstration Convertor (TDC) Stirling model, the energy flows and losses are shown at each step. In one of the steps, sub-cases were developed to investigate the sensitivity of the model to certain parameters. These sub-cases are helpful in clarifying the characteristics of the specific model and contribute to the accuracy of the simulation results. Finally, the model predictions were compared with TDC data, and then calibration parameters were adjusted to improve agreement with the data.
\end{abstract}

\begin{tabular}{|c|c|c|}
\hline$B S$ & $=$ & bounce space \\
\hline$C$ & $=$ & cooler \\
\hline$C S$ & $=$ & compression space \\
\hline$C W$ & $=$ & cooler wall \\
\hline$E S$ & $=$ & expansion space \\
\hline Exp.Data & $=$ & experimental data \\
\hline$H$ & $=$ & heater \\
\hline$H W$ & $=$ & heater wall \\
\hline Ind. Eff. & $=$ & indicated efficiency \\
\hline$K_{d}$ & $=$ & displacer spring constant \\
\hline$\dot{m}_{G t}$ & $=$ & gas flow, $\mathrm{kg} / \mathrm{s}$ \\
\hline MPress & $=$ & mean charge pressure, $\mathrm{MPa}$ \\
\hline Pphsr & $=$ & phasor pressure \\
\hline$P V$ & $=$ & pressure-volume \\
\hline PVPwr(bounce) & $=$ & pressure-volume power (bounce space) \\
\hline$P V P w r(c o m)$ & $=$ & pressure-volume power (compression space) \\
\hline$P V P w r(\exp )$ & $=$ & pressure-volume power (expansion space) \\
\hline Qstdy & $=$ & steady heat flow, W \\
\hline$R$ & $=$ & regenerator \\
\hline$R W$ & $=$ & regenerator wall \\
\hline Tcold & $=$ & cold-end temperature, $\mathrm{K}$ \\
\hline Thot & $=$ & hot-end temperature, $\mathrm{K}$ \\
\hline TotalPVPwr & $=$ & total pressure-volume power \\
\hline stdy & $=$ & steady density of gas, $\mathrm{kg} / \mathrm{m}^{3}$ \\
\hline
\end{tabular}

\footnotetext{
* Aerospace Engineer, Sest, Inc., 18000 Jefferson Park, Middleburg Heights, OH 44130, Member.

${ }^{\dagger}$ Aerospace Engineer, Sest, Inc., 18000 Jefferson Park, Middleburg Heights, OH 44130, Member.
} 


\section{Introduction}

S TIRLING convertors are being developed for potential use in future space science missions. The computer simulation of the Stirling convertor is an important part of this development effort. The simulation is used to predict convertor performance of the thermodynamic cycle. Today, Stirling engine and cooler designers, such as INFINIA Corp. (formerly Stirling Technology Company (STC)), and Sunpower, use Sage simulation software to model and design Stirling devices. Sage is a one-dimensional (1-D) steady-periodic Stirling cycle design and simulation program developed by Gedeon Associates of Athens, Ohio. ${ }^{1}$ This report explains how Sage was used to construct a Stirling convertor model via a step-by-step development process, shows some sensitivity study results for the model, and compares predictions of the model with engine data.

Stirling engine research at NASA Glenn Research Center (GRC) started with the kinematic automotive Stirling engine development project to achieve higher automotive engine efficiency. ${ }^{2}$ In the 1980's, research and development of free-piston Stirling convertors (engine plus linear alternator) as the power source for space missions started, because the Stirling convertor is highly efficient which leads to low-mass systems. As a part of the effort, Stirling computational models were developed to predict convertor performance and aid in their design.

Modeling of the Stirling cycle by NASA GRC began in the 1970's. ${ }^{3-4}$ Later, two 1-D Stirling design codes, GLIMPS and HFAST were used to compare engine simulation results with experimental results. ${ }^{5}$ GLIMPS was a predecessor of the Sage 1-D Stirling simulation code developed by Gedeon Associates ${ }^{1}$. HFAST is a 1-D Stirling cycle simulation harmonic code written in FORTRAN, and developed by Mechanical Technology, Inc. ${ }^{6}$ Later the modeling effort was extended to two-dimensional (2-D) simulation by Cleveland State University, ${ }^{7,8}$ and today there are ongoing multidimensional simulation efforts using commercial simulation codes. ${ }^{9-12}$. Ebiana and Pawar of Cleveland State University developed a Sage free-piston model, with both power piston and displacer modeled as spring-mass-damper systems. ${ }^{13}$

Sage is the most widely used Stirling cycle analysis code however; a step-by-step method of constructing such a model has not been described in the open literature. This paper describes one step-by-step procedure for modeling the Technology Demonstration Convertor (TDC), which was designed and manufactured by INFINIA Corp and is being tested at NASA GRC.

The evolution of this particular Stirling engine model is explained through increasingly complex cases while tracking the power produced, heat flow, losses, and energy balance. This method starts from a simple model, and each step adds component(s) that make the model more realistic, and complex. This technique shows the impact of the evolution of the model on its predictions through a number of stages.

Sage software represents each part of the Stirling device visually by component, in a window that shows connections between model components. Components of the model are connected by several types of connectors, such as heat flow, mass flow, etc. In this study, the operating conditions were kept the same for all major cases. However, some sub-cases were run by changing certain engine parameters in order to study their effect on the Stirling cycle.

The energy flows are shown in each step as the engine model evolves, to show the changes in power produced, heat flow and in energy losses. Energy balances were carefully checked for each case.

\section{Technology Demonstration Convertor Description}

A Stirling convertor manufactured by INFINIA Corp. was simulated, as shown in Fig. 1. The TDC is a gammatype free-piston Stirling convertor. The peak electric power output is about 55 to $64 \mathrm{We}$ depending on the operating condition. Heat is input at the heater head at temperatures up to $650^{\circ} \mathrm{C}$. The power piston and displacer are supported by flexures. This system consists of two major areas: the working space in the heater head and the bounce space in the pressure vessel. The main thermal energy exchange happens in the working space, as the displacer drives oscillating-flow through the heat exchangers in series (heater, regenerator, and cooler). In the pressure vessel, a power piston oscillates, resulting in changes in volume of the compression space and oscillatingpressure in the working fluid (helium). A linear alternator is attached to the power piston to convert the oscillating motion to electric power, which appears as damping on the power piston. The Sage simulations described in this paper concentrated on the working space, using an assumed alternator efficiency of $82 \%$ to convert the cycle power into electric power. 


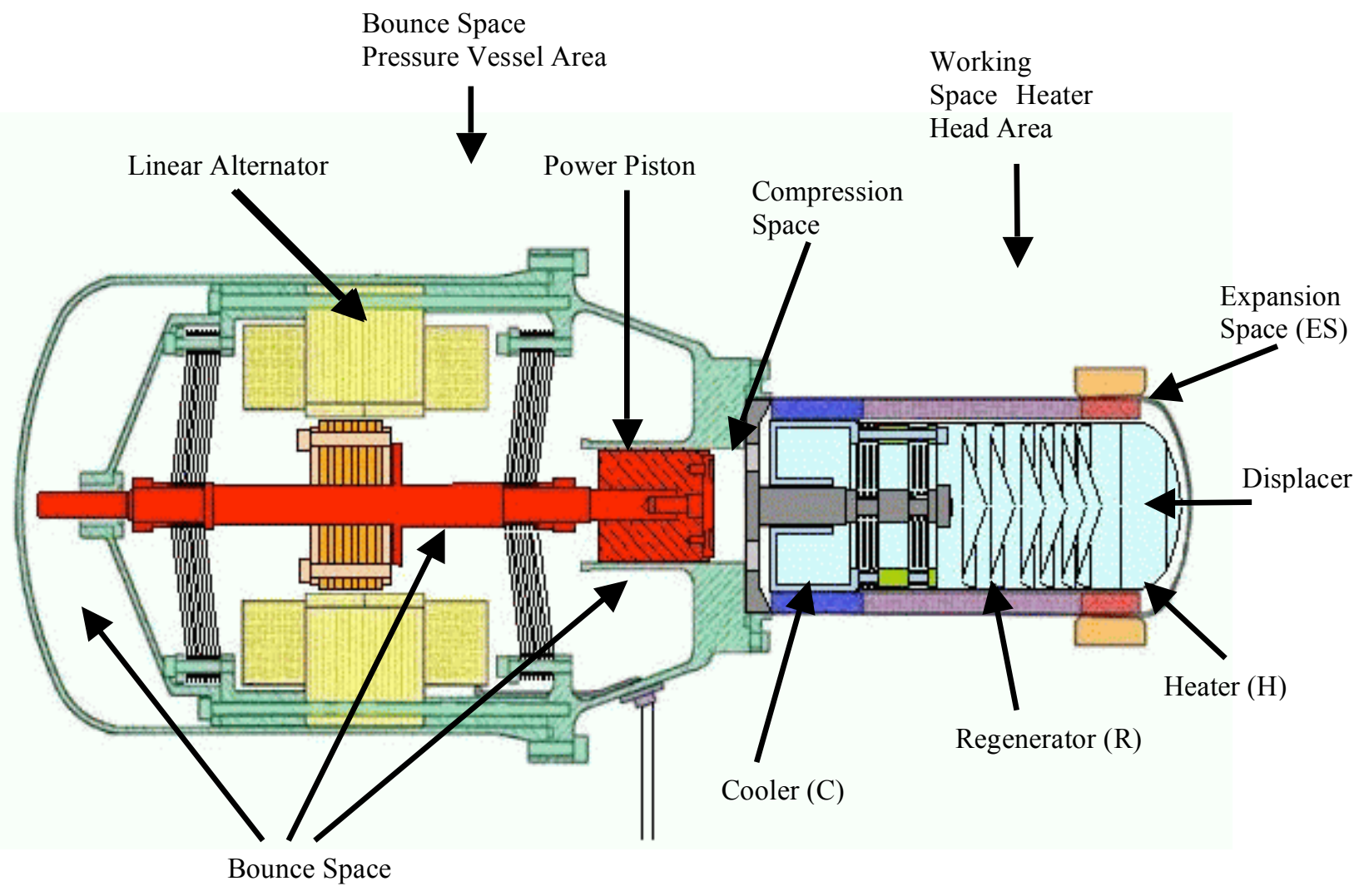

Figure 0. Technology Demonstration Convertor (TDC).

\section{Step-by-Step Model}

\section{A. Operating Conditions}

For the major cases shown in this study, the following operating conditions were assumed:

$\begin{array}{lll}\text { Hot-End Temperature } & \text { Thot (K) } & 922.1 \\ \text { Cold-End Temperature } & \text { Tcold (K) } & 373.5 \\ \text { Mean Pressure } & \text { MPress (MPa) } & 2.496 \\ \text { Frequency } & \text { Freq (Hz) } & 81.2\end{array}$

These conditions result in a Carnot efficiency of $59.5 \%$ based on Thot and Tcold.

\section{B. Energy Flow Diagrams}

Energy flow diagrams for each case are shown as indicated in the schematic in Fig. 2. The numerical values for the energy flows defined in Fig. 2 were taken from the Sage model output listing for each case. 


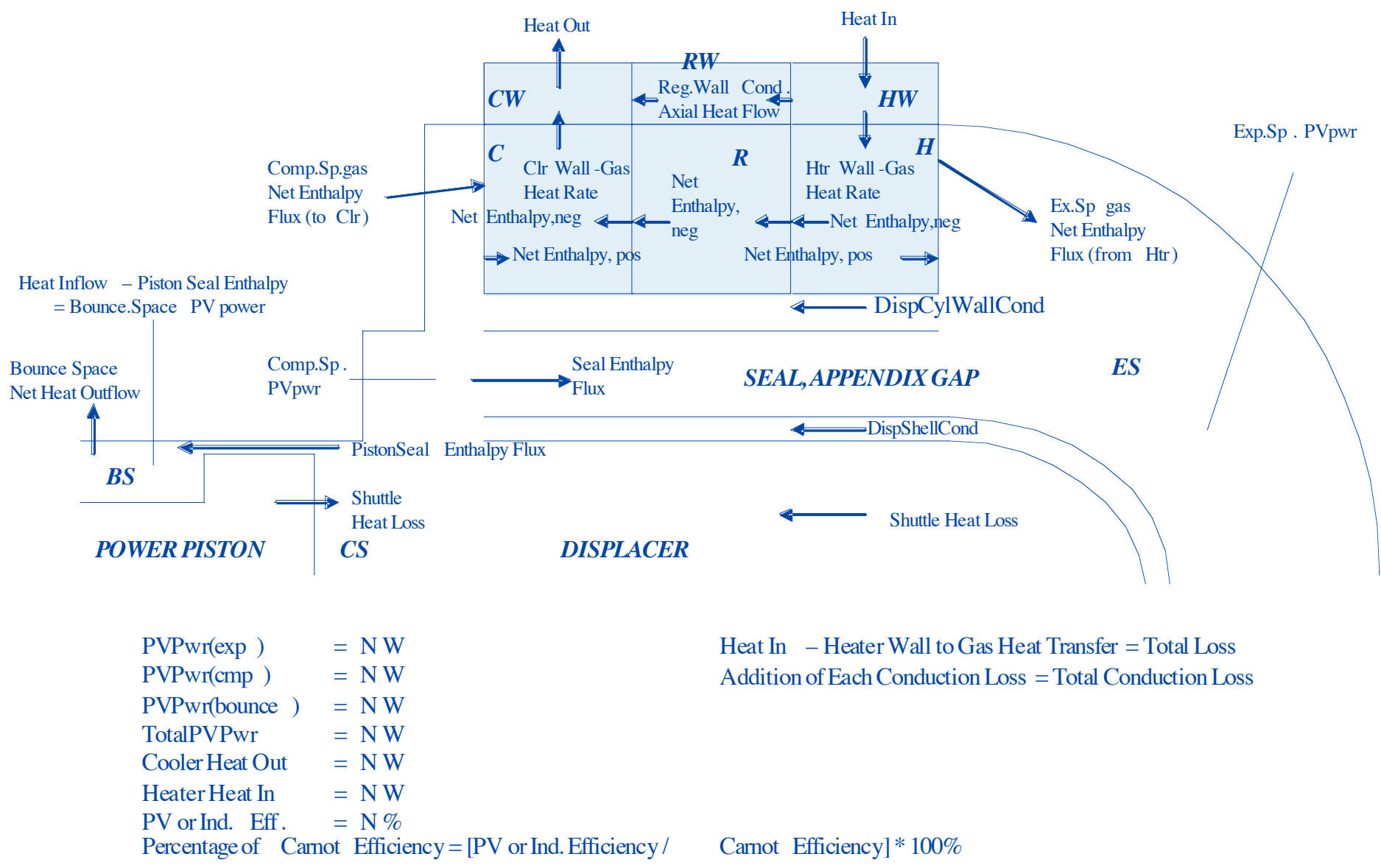

Figure 2. Form of energy flow diagrams used for Sage TDC model cases.

\section{Case 1 (Base Model)}

The first case starts with the most simple structure for the Sage TDC model. This model contains the basic components for a Stirling cycle working space; constrained power piston, constrained displacer, heat exchangers (heater, regenerator, and cooler), expansion and compression spaces. The Sage model elements were selected, and connected, to represent these components as shown in Fig. 3a. The Sage model was run (solved), and an output listing which defines the power and heat flows was generated. From this Sage output listing for the Case 1 model, the energy flows shown in Fig. $3 \mathrm{~b}$ were taken. The energy flow quantities shown in Fig. $3 \mathrm{~b}$ can be defined by reference to the energy flow names shown in Fig. 2. These results from the simple model (Fig. 3b) show the very basic energy and heat flows without some of the heat conduction and other losses included. 

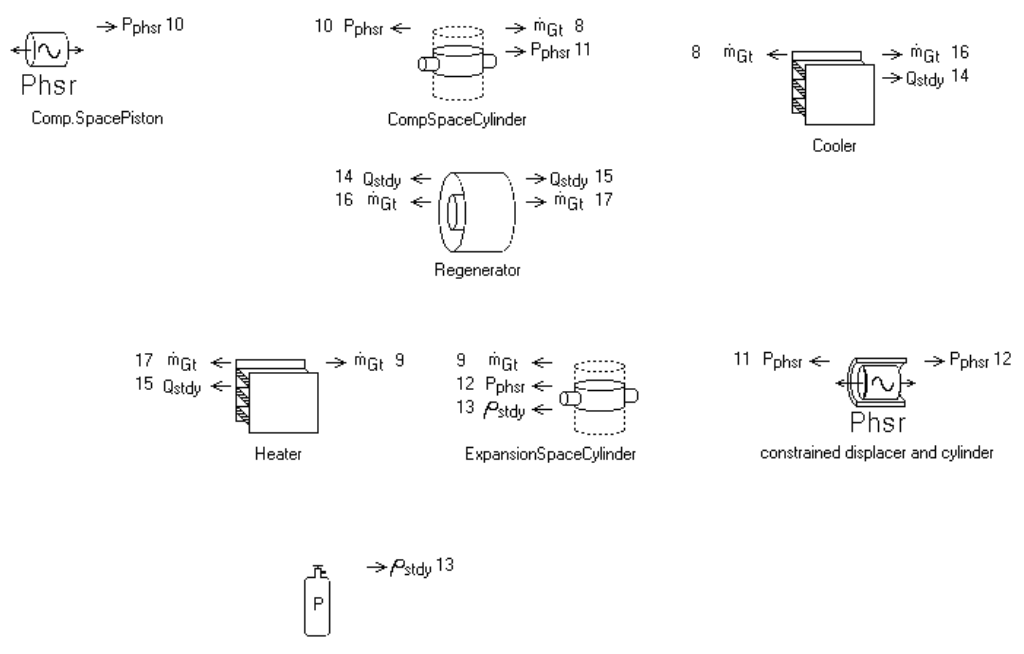

Figure 3a. Sage diagram showing interconnection of Sage Case 1 TDC model components.

This Case 1 model shown in Fig. $3 \mathrm{a}$ is the base model for comparison with the later cases.

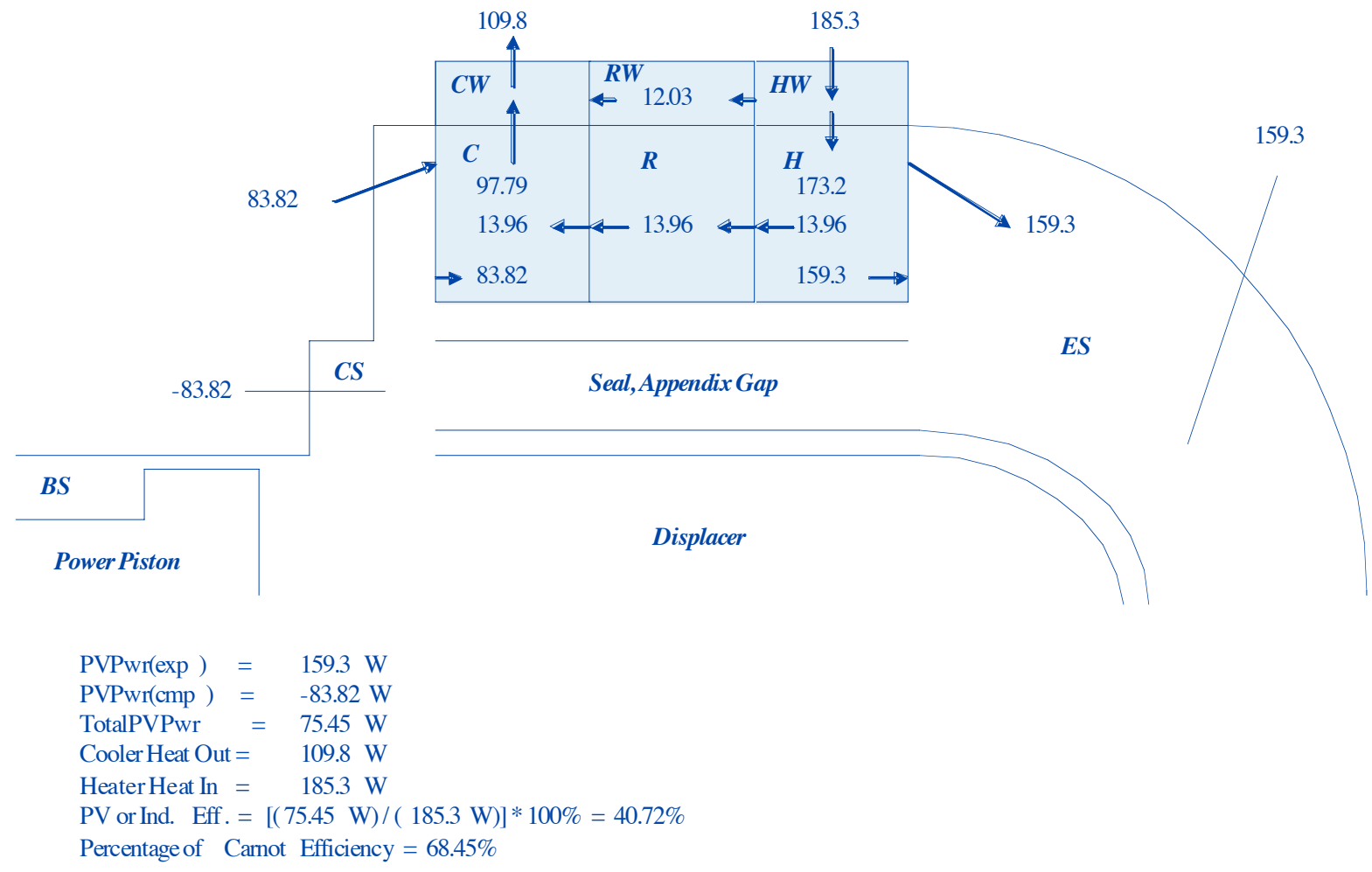

Figure 3b. Energy flow diagram for Sage Case 1 TDC model results. 
Table I. Sage Simulation Results - Case 1 (Base Model)

\begin{tabular}{|l|c|c|c|c|c|c|c|}
\hline & $\begin{array}{c}\text { Heater } \\
\text { Heat In } \\
\text { (W) }\end{array}$ & $\begin{array}{c}\text { Cooler } \\
\text { Heat } \\
\text { Out } \\
\text { (W) }\end{array}$ & $\begin{array}{c}\text { Exp.Space } \\
\text { PVPwr }\end{array}$ & $\begin{array}{c}\text { Comp.Sp. } \\
\text { PVPwr } \\
\text { (W) }\end{array}$ & $\begin{array}{c}\text { Total } \\
\text { PVPwr } \\
\text { (W) }\end{array}$ & $\begin{array}{c}\text { Heat } \\
\text { Cond } \\
\text { Loss } \\
\text { (W) }\end{array}$ & $\begin{array}{c}\text { PV } \\
\text { Efficiency } \\
\%\end{array}$ \\
\hline Case 1 & 185.3 & 109.8 & 159.3 & 83.8 & 75.5 & 12.1 & 40.7 \\
\hline
\end{tabular}

The Sage prediction results shown in Fig. $3 \mathrm{~b}$ for the Case $1 \mathrm{TDC}$ model indicate, for example, total PV Power $=$ 75.45 W, Heat Into Heater $=185.3 \mathrm{~W}$, Heat Out of Cooler $=109.8 \mathrm{~W}$, and PV Efficiency $=40.7 \%$. This is also summarized in Table I. Tables of this form will also be used to compare results for the various cases. Fig. $3 \mathrm{~b}$ also shows fluid enthalpy flows between the fluid components.

\section{Case 2 (Adds displacer shell \& cylinder liner conduction losses)}

In Case 2, the conduction through the displacer cylinder liner and displacer shell was added as shown in Fig. 4a. These were added via Sage "bar conductor" elements. Sage Case 2 model numerical results are shown in the energy-flow diagram of Fig. 4b. By comparison with the energy flow analysis of Case 1, the impact of the new heat conduction loss is easily found. The difference in pressure phase angle between the experimental data and simulation result is $5.89^{\circ}$, with the simulation indicating a greater phase angle.

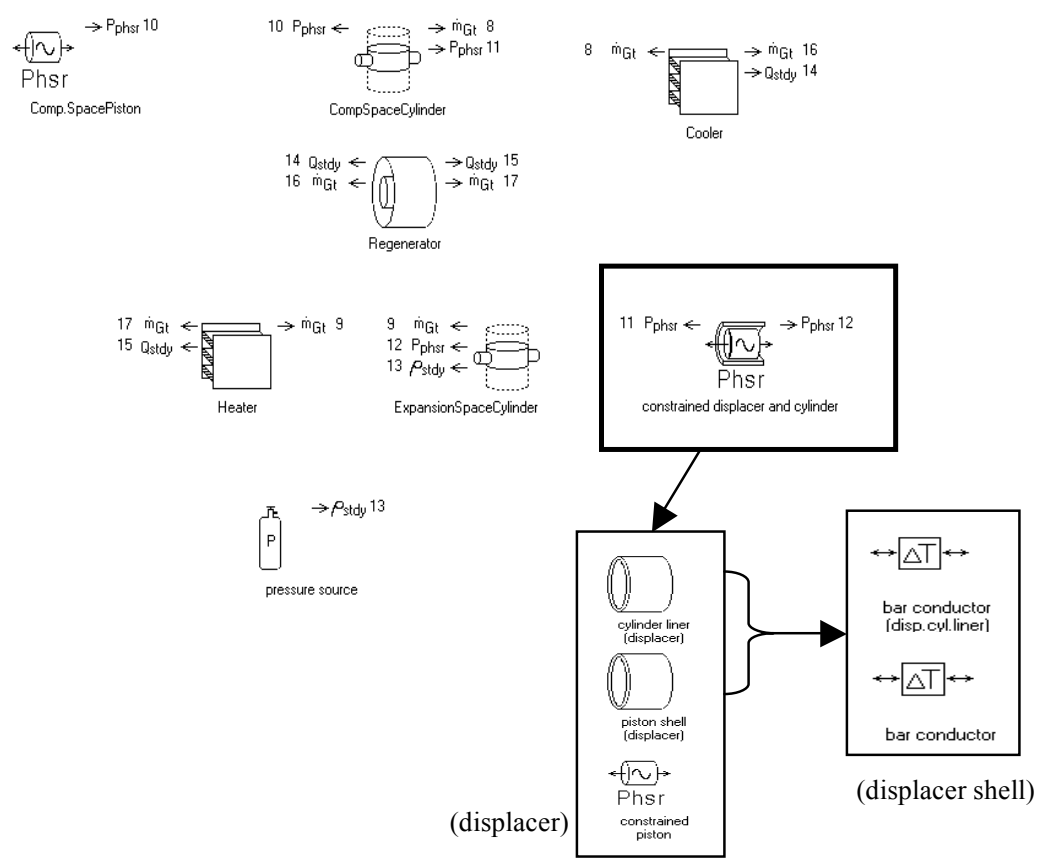

Figure 4a. Sage diagram showing interconnection of Sage Case 2 TDC model components.

The two new heat conduction losses are indicated in the Fig. 4b energy-flow diagram for Case 2 in italicized font. The Sage results shown for the Case $2 \mathrm{TDC}$ model indicate Total PV Power $=75.2 \mathrm{~W}$, Heat Into Heater $=$ $199.8 \mathrm{~W}$, Heat Out of Cooler $=124.6 \mathrm{~W}$, and PV Efficiency $=37.6 \%$. There was no change in the pressure phase angle from Case 1 to Case 2. 


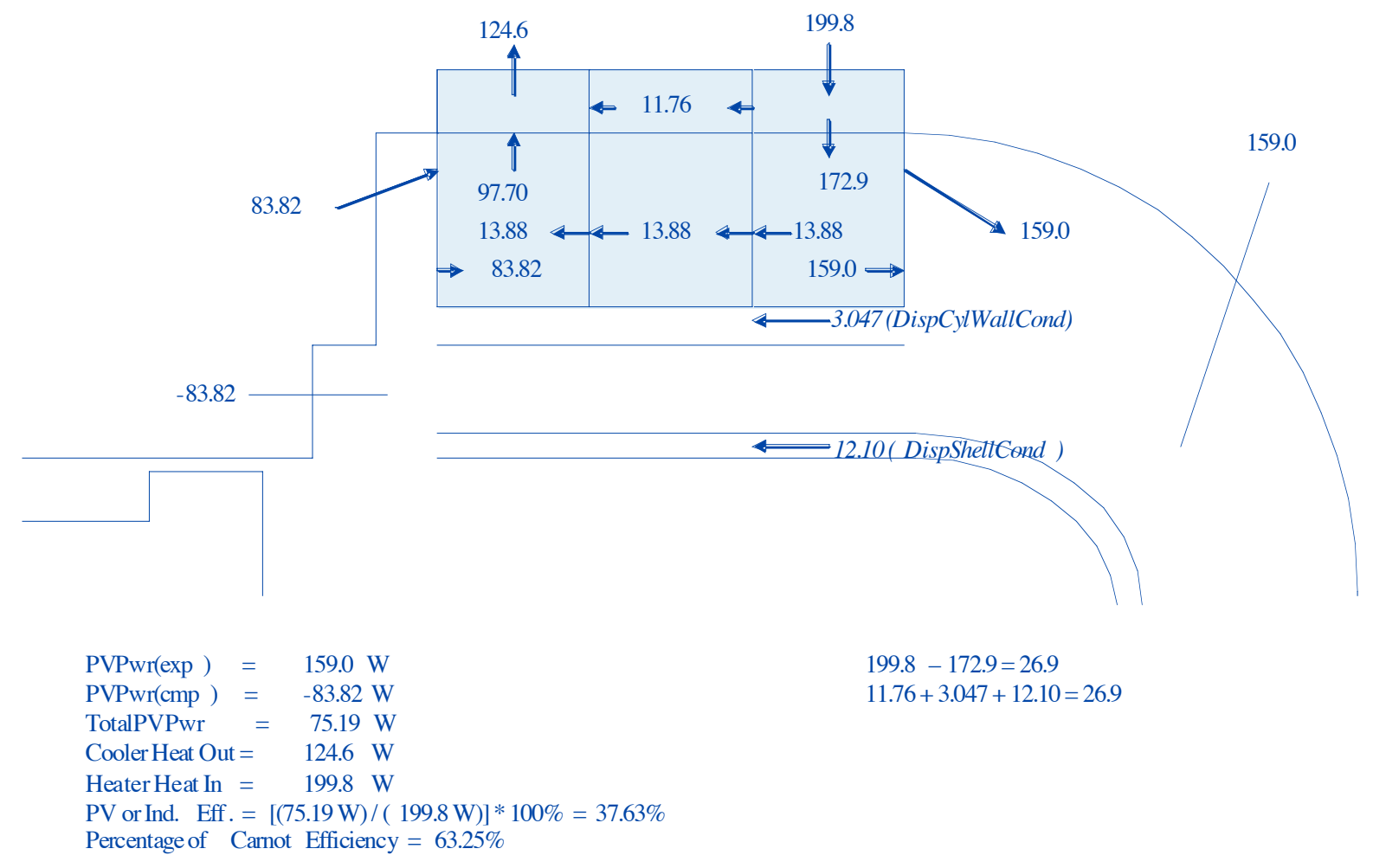

Figure 4b. Sage diagram showing interconnection of Sage Case 2 TDC model components.

Table II. Sage Simulation Result Comparison, Case 1 and Case 2 (Shows effect of adding displacer shell \& cylinder liner heat conduction losses)

\begin{tabular}{|l|c|c|c|c|c|c|c|}
\hline & $\begin{array}{c}\text { Heater } \\
\text { Heat In } \\
(\mathrm{W})\end{array}$ & $\begin{array}{c}\text { Cooler } \\
\text { Heat } \\
\text { Out } \\
(\mathrm{W})\end{array}$ & $\begin{array}{c}\text { Exp.Space } \\
\text { PVPwr } \\
(\mathrm{W})\end{array}$ & $\begin{array}{c}\text { Comp.Sp.PVPwr } \\
\text { (W) }\end{array}$ & $\begin{array}{c}\text { Total } \\
\text { PVPwr } \\
(\mathrm{W})\end{array}$ & $\begin{array}{c}\text { Heat } \\
\text { Cond } \\
\text { Loss } \\
(\mathrm{W})\end{array}$ & $\begin{array}{c}\text { PV } \\
\text { Efficiency } \\
\%\end{array}$ \\
\hline Case 1 & 185.3 & 109.8 & 159.3 & 83.8 & 75.5 & 12.1 & 40.7 \\
\hline Case 2 & 199.8 & 124.6 & 159.0 & 83.8 & 75.2 & 26.9 & 37.6 \\
\hline Difference & 14.5 & 14.8 & -0.3 & 0 & -0.26 & 14.8 & -3.1 \\
\hline
\end{tabular}

Table II compares some of the major Case $1 \&$ Case 2 results, and shows their difference from Case 1 to Case 2. From Case 1 to Case 2, the Total PV Power decreased slightly when the heat conduction losses were added. The heat conduction losses essentially added to the heat in required and the heat out, and should have little to no effect on power. This is because the temperatures were fixed in these simulations; the conduction loss should have no impact on the thermodynamic cycle. It is believed that the slight difference in the Total PV Power was caused by the slightly different paths that Sage took to get to the two solutions. The PV Efficiency was reduced because the Heat In was increased by the heat conduction losses. The PV efficiency decreased by more than 3 percentage points, primarily due to the added heat conduction loss. The difference in pressure phase angle between the experimental data and the Case 2 simulation result was $5.83^{\circ}$, with the pressure phase angle from the simulation results being larger.

\section{E. Case 3 (Addition of bounce space and power-piston seal)}

Case 3 involved the addition of the bounce space (variable volume surrounding the alternator in Fig. 1) and the power piston seal. Fig. 5a shows the model component interconnections with the addition of the bounce space and 
power piston seal into the Sage model of Case 2. The power piston seal was added within the constrained piston model component. By this addition, piston seal loss, piston shuttle loss, and heat loss from the bounce space were incorporated into the energy balance. Sage predictions for Case 3 are summarized in the energy-flow diagram of Fig. $5 b$.
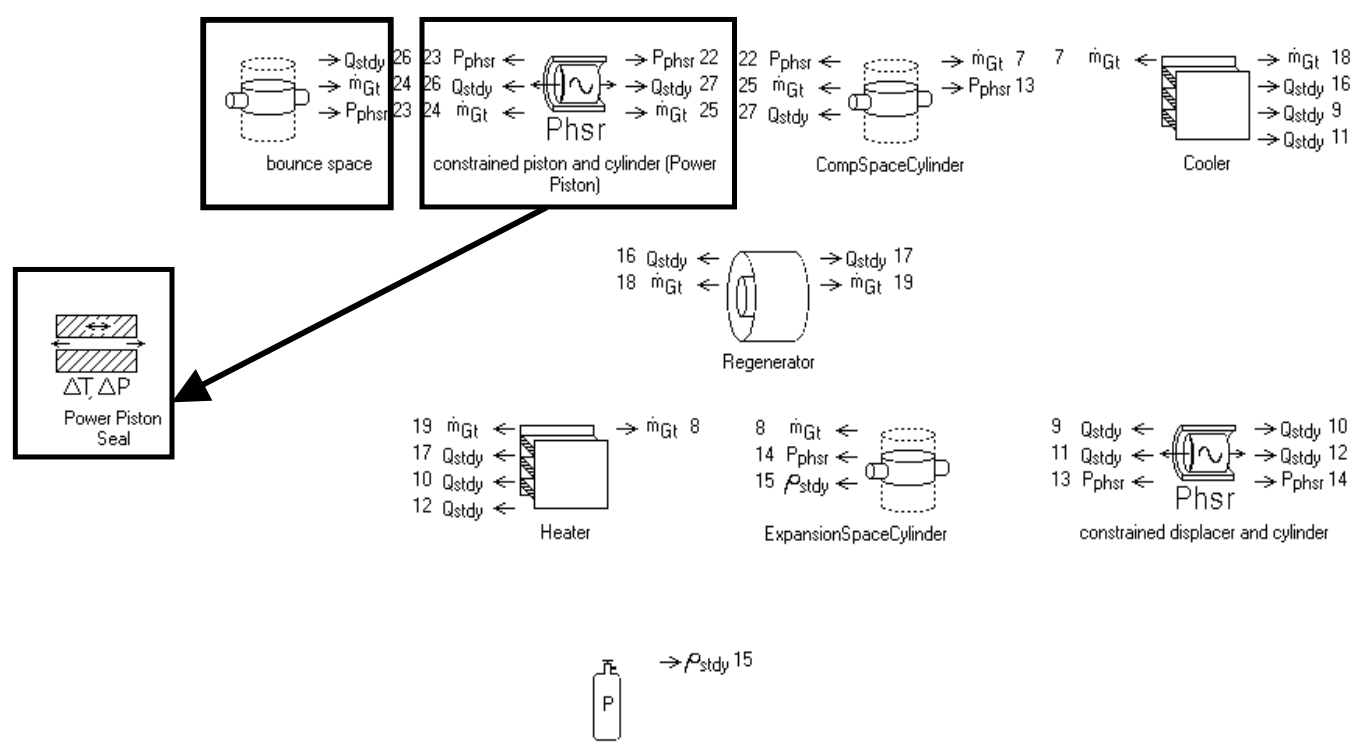

Figure 5a. Sage diagram showing interconnection of Sage Case 3 TDC model components.

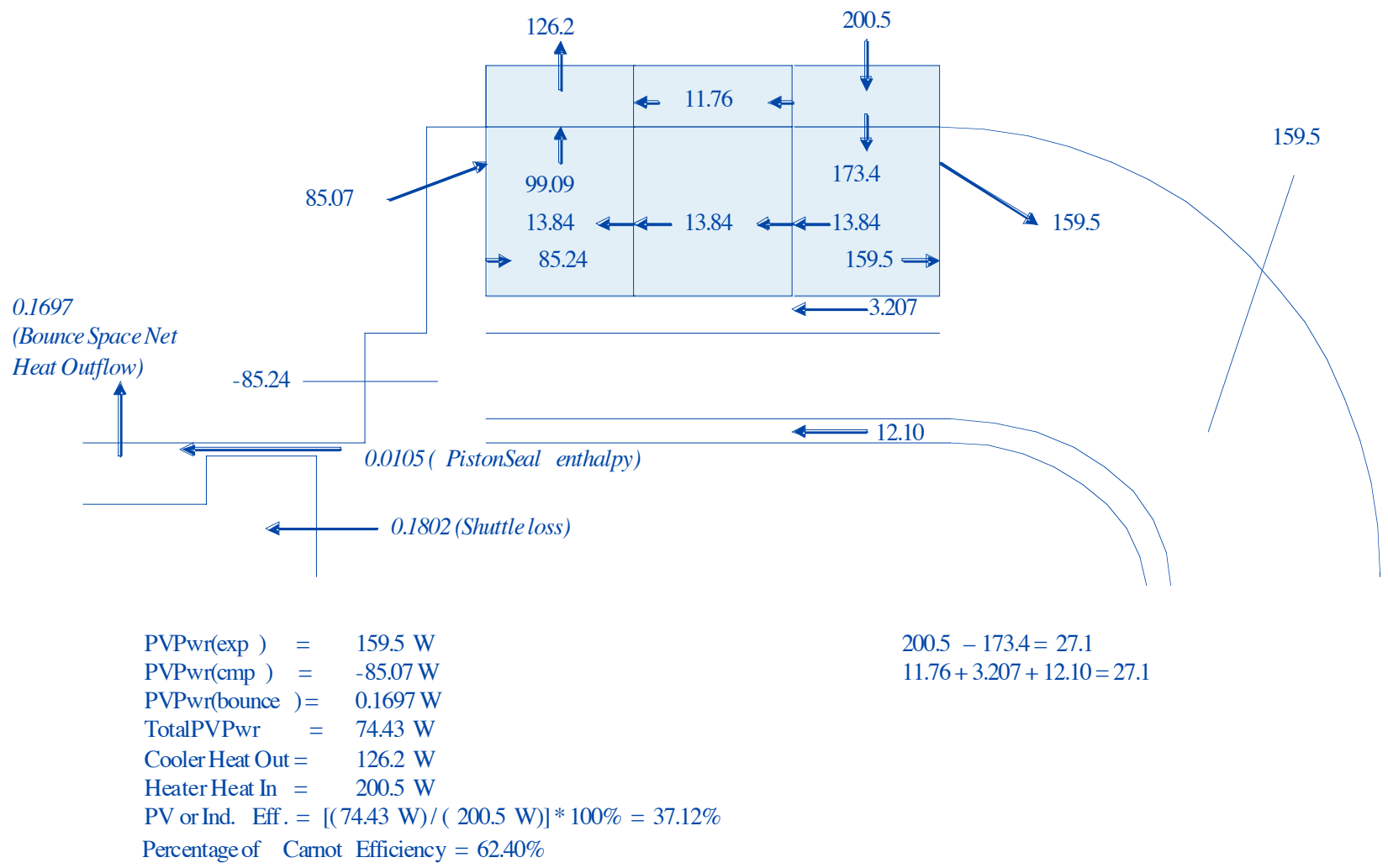

Figure 5b. Energy flow diagram for Sage Case 3 TDC model results. 
The predictions for Case 2 and Case 3 are summarized in Table III. Table III shows that the addition of the bounce space and the power piston seal resulted in increases in heat in and heat out, and a decrease in Total PV Power, all approximately $1 \mathrm{~W}$. A PV Efficiency reduction of about 0.5 percentage points resulted. The pressure phase angle was reduced by $0.3^{\circ}$ from Case 2 to Case 3 . The pressure phase angle difference between the experimental data and simulation results was $5.48^{\circ}$, with a larger value for the simulation results.

Table III. Sage Simulation Result Comparison - Case 2 and Case 3 (Shows effect of adding bounce space and power-piston seal)

\begin{tabular}{|l|c|c|c|c|c|c|c|}
\hline & $\begin{array}{c}\text { Heater } \\
\text { Heat In } \\
(\mathrm{W})\end{array}$ & $\begin{array}{c}\text { Cooler } \\
\text { Heat } \\
\text { Out } \\
(\mathrm{W})\end{array}$ & $\begin{array}{c}\text { Exp.Space } \\
\text { PVPwr } \\
(\mathrm{W})\end{array}$ & $\begin{array}{c}\text { Comp.Sp.PVPwr } \\
\text { (W) }\end{array}$ & $\begin{array}{c}\text { Total } \\
\text { PVPwr } \\
(\mathrm{W})\end{array}$ & $\begin{array}{c}\text { Heat } \\
\text { Cond } \\
\text { Loss } \\
(\mathrm{W})\end{array}$ & $\begin{array}{c}\text { PV } \\
\text { Efficiency } \\
\%\end{array}$ \\
\hline Case 2 & 199.8 & 124.6 & 159.0 & 83.8 & 75.2 & 26.9 & 37.6 \\
\hline Case 3 & 200.5 & 126.2 & 159.5 & 85.1 & 74.5 & 27.1 & 37.2 \\
\hline Difference & 0.7 & 1.6 & 0.5 & 1.3 & -0.7 & 0.2 & -0.4 \\
\hline
\end{tabular}

\section{F. Case 4 (Addition of displacer-body seal and appendix gap)}

The displacer-body seal and appendix gap were added in moving from Case 3 to Case 4. This addition was accomplished by adding the temperature distribution along with the seal and appendix gap dimensions via the Sage seal and appendix gap elements inside the "constrained displacer and cylinder" element, as indicated in Fig. 6a. The temperature distribution was assumed to be linear along the axial length of the appendix gap. Sage predictions for Case 4 are summarized in the energy-flow diagram of Fig. 6b. Changes in the Sage model predictions in going from Case 3 to Case 4 are summarized in Table IV.

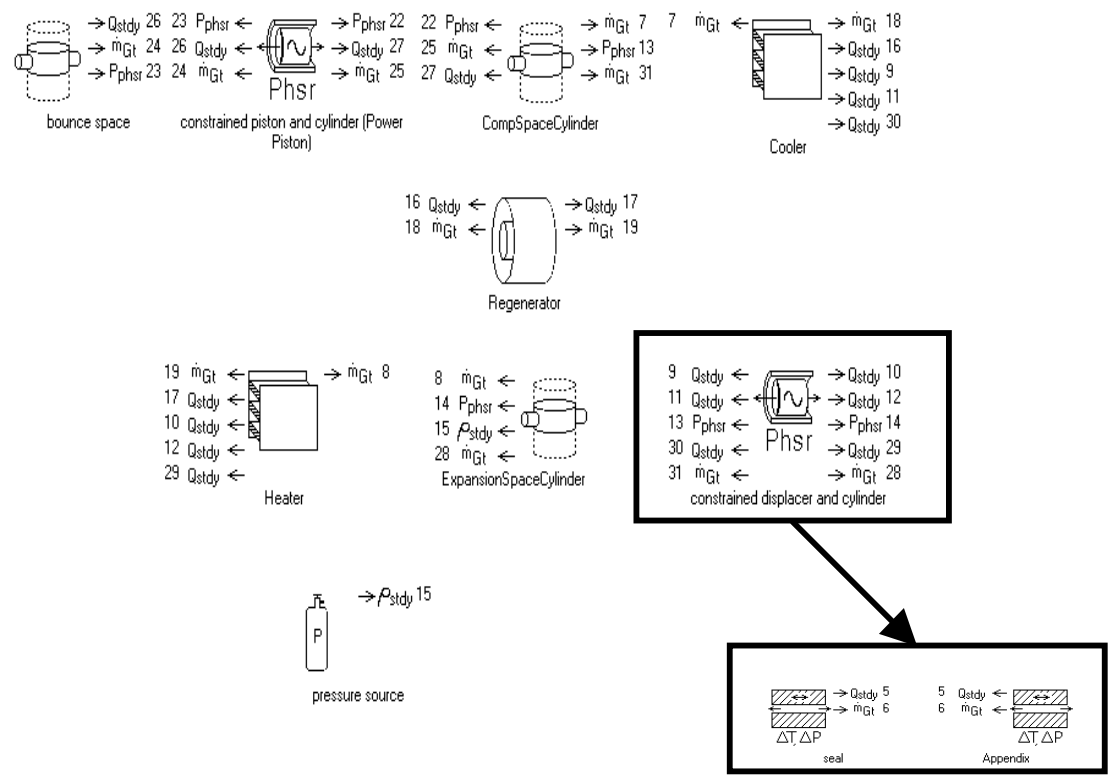

Figure 6a. Sage diagram showing interconnection of Sage Case 4 TDC model components. 


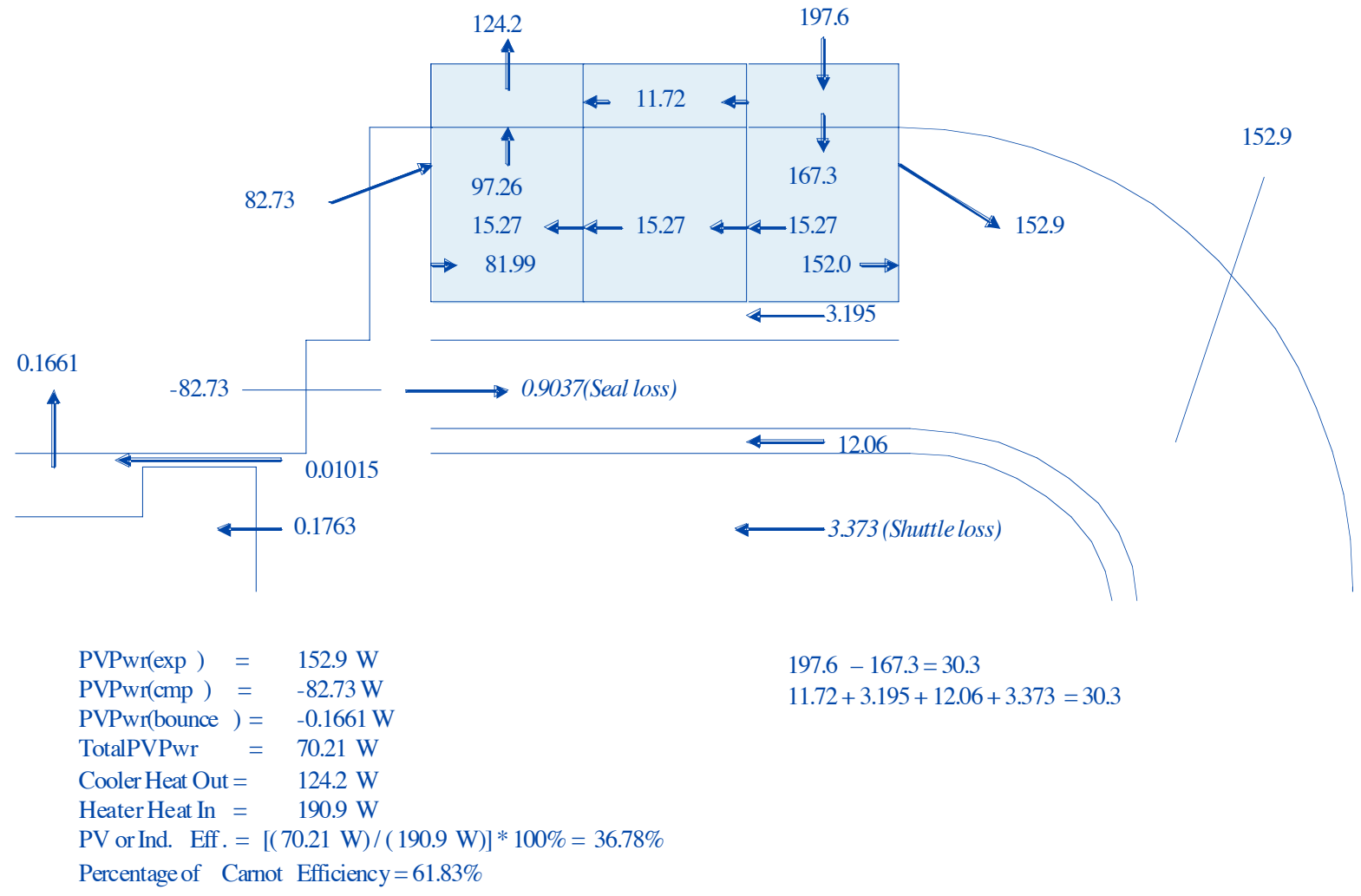

Figure 6b. Energy flow diagram for Sage Case 4 TDC model results.

Table IV. Sage Simulation Result Comparison - Case 3 and Case 4 (Shows effect of adding displacer-body seal and appendix gap)

\begin{tabular}{|l|c|c|c|c|c|c|c|}
\hline & $\begin{array}{c}\text { Heater } \\
\text { Heat In } \\
(\mathrm{W})\end{array}$ & $\begin{array}{c}\text { Cooler } \\
\text { Heat } \\
\text { Out } \\
(\mathrm{W})\end{array}$ & $\begin{array}{c}\text { Exp.Space } \\
\text { PVPwr } \\
(\mathrm{W})\end{array}$ & $\begin{array}{c}\text { Comp.Sp.PVPwr } \\
(\mathrm{W})\end{array}$ & $\begin{array}{c}\text { Total } \\
\text { PVPwr } \\
(\mathrm{W})\end{array}$ & $\begin{array}{c}\text { Heat } \\
\text { Cond } \\
\text { Loss } \\
(\mathrm{W})\end{array}$ & $\begin{array}{c}\text { PV } \\
\text { Efficiency } \\
\%\end{array}$ \\
\hline Case 3 & 200.5 & 126.2 & 159.5 & 85.1 & 74.5 & 27.1 & 37.2 \\
\hline Case 4 & 190.9 & 124.2 & 152.9 & 82.7 & 70.2 & 23.6 & 36.8 \\
\hline Difference & -9.6 & -2.0 & -6.6 & -2.4 & -4.3 & -3.5 & -0.4 \\
\hline
\end{tabular}

Table IV shows a substantial reduction of the Total PV Power (4.3 W), and a small reduction of PV Efficiency via addition of the displacer-body seal and the appendix gap. The pressure phase angle was reduced by $0.45^{\circ}$ from Case 3 to Case 4 . This can be attributed to some of the working fluid leaking past the displacer and not going through the heat exchangers since the heating and cooling of the working fluid is the largest source of the pressure phase angle. As an example, if there were no heating and cooling of the working fluid, the working space volume would essentially be a gas spring with nearly no phase angle at all. The difference in pressure phase angle between the experimental data and simulation result decreased to $5.0^{\circ}$ with the simulation pressure phase angle still being larger.

\section{G. Case 5 (Addition of displacer-rod seal and the volume inside the displacer)}

In Case 5, the displacer rod seal and the variable volume inside of the displacer were added. These additions were accomplished by adding the volume (generic cylinder) and the displacer rod (constrained piston and cylinder element) to the Sage model as shown in Fig. 7a. It can be determined via the numbers on the mass-flow connectors 
$\left(\dot{m}_{G t}\right.$ ) that the displacer rod seal connects the compression space to the volume inside of the displacer. Sage predictions for Case 5 are summarized in Fig. 7b. The changes in the Sage model predictions in going from Case 4 to Case 5 are summarized in Table V.

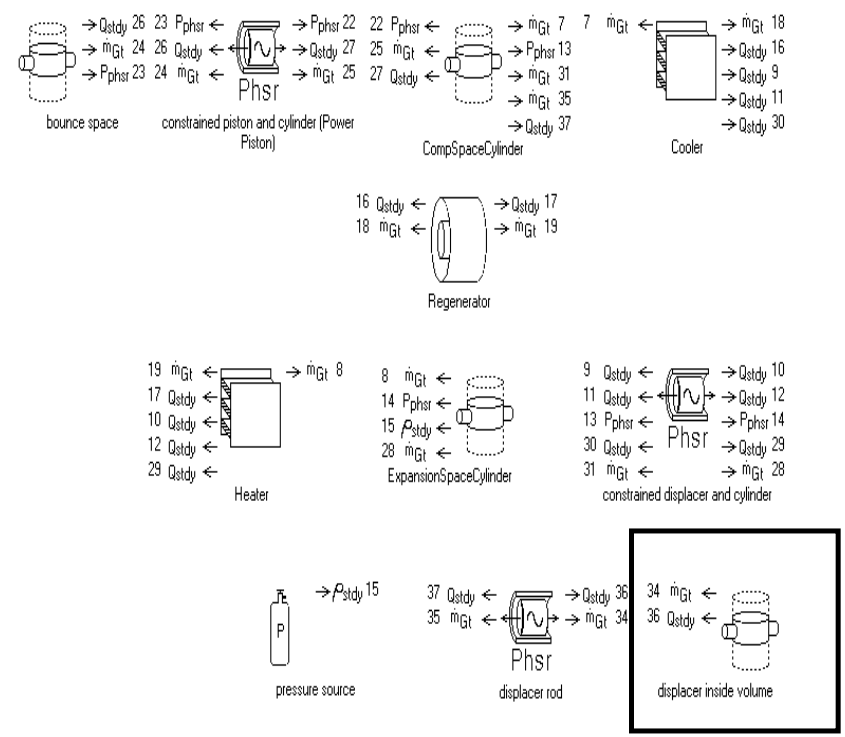

Figure 7a. Sage diagram showing interconnection of Sage Case 5 TDC model components. 


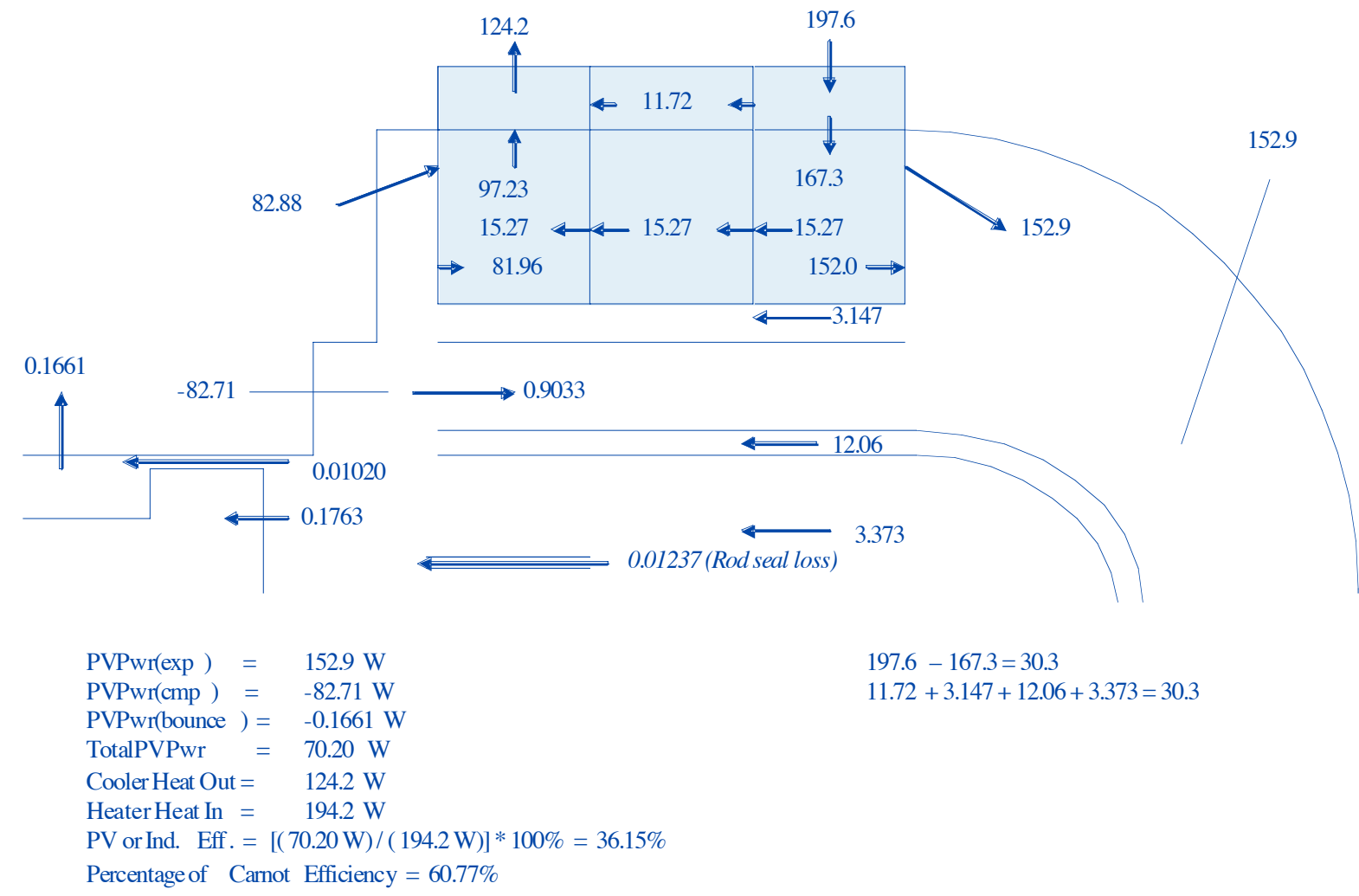

Figure 7b. Energy flow diagram for Sage Case 5 TDC model results.

Table V. Sage Simulation Result Comparison - Case 4 and Case 5 (Shows effect of adding displacer-rod seal and volume inside the displacer)

\begin{tabular}{|l|c|c|c|c|c|c|c|}
\hline & $\begin{array}{c}\text { Heater } \\
\text { Heat In } \\
(\mathrm{W})\end{array}$ & $\begin{array}{c}\text { Cooler } \\
\text { Heat } \\
\text { Out } \\
(\mathrm{W})\end{array}$ & $\begin{array}{c}\text { Exp.Space } \\
\text { PVPwr } \\
(\mathrm{W})\end{array}$ & $\begin{array}{c}\text { Comp.Sp.PVPwr } \\
\text { (W) }\end{array}$ & $\begin{array}{c}\text { Total } \\
\text { PVPwr } \\
(\mathrm{W})\end{array}$ & $\begin{array}{c}\text { Heat } \\
\text { Cond } \\
\text { Loss } \\
(\mathrm{W})\end{array}$ & $\begin{array}{c}\text { PV } \\
\text { Efficiency } \\
\%\end{array}$ \\
\hline Case 4 & 190.9 & 124.2 & 152.9 & 82.7 & 70.2 & 23.6 & 36.8 \\
\hline Case 5 & 197.6 & 124.2 & 152.9 & 82.7 & 70.2 & 30.3 & 35.5 \\
\hline Difference & 6.7 & 0 & 0 & -0.0 & -0.0 & 6.7 & -1.3 \\
\hline
\end{tabular}

The results shown in Table V show essentially no change in Total PV Power, but a loss in PV Efficiency of 1.26 percentage points as a result of an increase in heat input when the displacer rod seal model was added. The pressure phase angle had no change from Case 4 to 5 . The pressure phase angle difference between the experimental data and simulation results remained unchanged at $5.0^{\circ}$. This indicates that the seal between the working space and the volume inside of the displacer allows no significant leakage. The pressure amplitude was not reduced nor was the pressure phase angle reduced, resulting in the same Total PV Power as when there was no leak path being modeled.

\section{H. Case 6 (Change from constrained to "free" displacer)}

An investigation undertaken in this step-by-step model development was to change the displacer operation from constrained mode to "free" or unconstrained motion. This would show the response of the displacer (motion) to the 
pressure wave as calculated by Sage, which could then be compared to the data. The free-displacer movement is determined by the displacer mass, the displacer spring rate, and the damping that it experiences, when the pressure forces act on it. In the constrained mode, the displacer movement is specified by a set amplitude and phase angle relative to the power piston. While the displacer mass and the spring rate of the flexure can be measured directly, the damping that it experiences is complex, being based primarily on the oscillating flow losses in the heat exchangers and manifolds, and to some lesser extent, on the other displacer losses such as leakage. It was felt that this study could provide some insight into Sage's ability to model the losses acting on the displacer. Also, since the size of the displacer rod of the TDC being modeled was accurately known, the power supplied to drive the displacer was also known. This could be compared to the analytical predictions. The input parameters necessary for definition of the free-displacer model were mass, spring rate, and damping coefficient of the displacer.

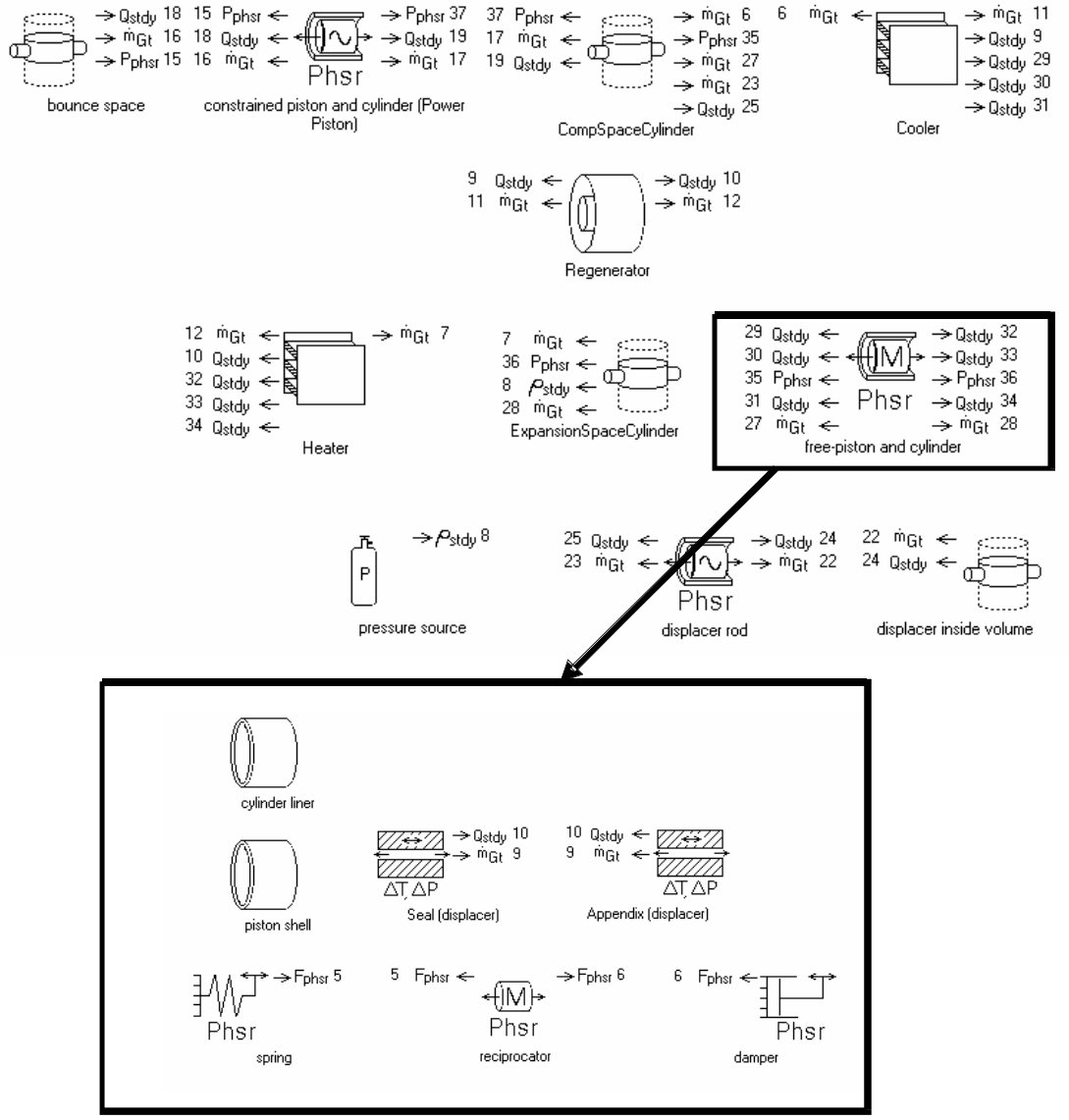

Figure 8a. Sage diagram showing interconnection of Sage Case 6 TDC model components.

The spring rate and damping coefficient had to be defined to complete the Case 6 free-displacer TDC model. First, a spring constant was obtained experimentally by the INFINIA Corp. and was used as a starting point. The Sage mapping function was then used to select a final set of constants. The mapping function was used to obtain a sequence of solutions over a specified range of input variables. In this case, mapping was used to explore combinations of spring rates and damping to best fit the Sage simulation results with the experimental data. Therefore, for this case, the experimental data measured displacer amplitude and phase angle were not used as inputs to the model, rather, they were part of the output that was being studied. The simulation results were compared with experimental data based on the following output parameters: Electrical Output Power (PV Power times the assumed 
alternator efficiency), Overall Efficiency, Pressure Phase Angle, Pressure Amplitude, and Displacer Amplitude. Best overall agreement was obtained when Sage indicated a spring rate some 13\% greater than the measured value. This discrepancy could be a result of uncertainty in the non-linear element of the experimental spring rate equation. The corresponding damping coefficient was $2.550 \mathrm{E}-2(\mathrm{~N} \cdot \mathrm{s}) / \mathrm{m}$. The selection of the combination of spring constant and damping coefficient was based on overall agreement with the experimental data with special attention having been paid to the pressure phase angle. As a result of this initial study, there will be some future effort to try to further compare the modeled displacer dynamics to the measured experimental data results..

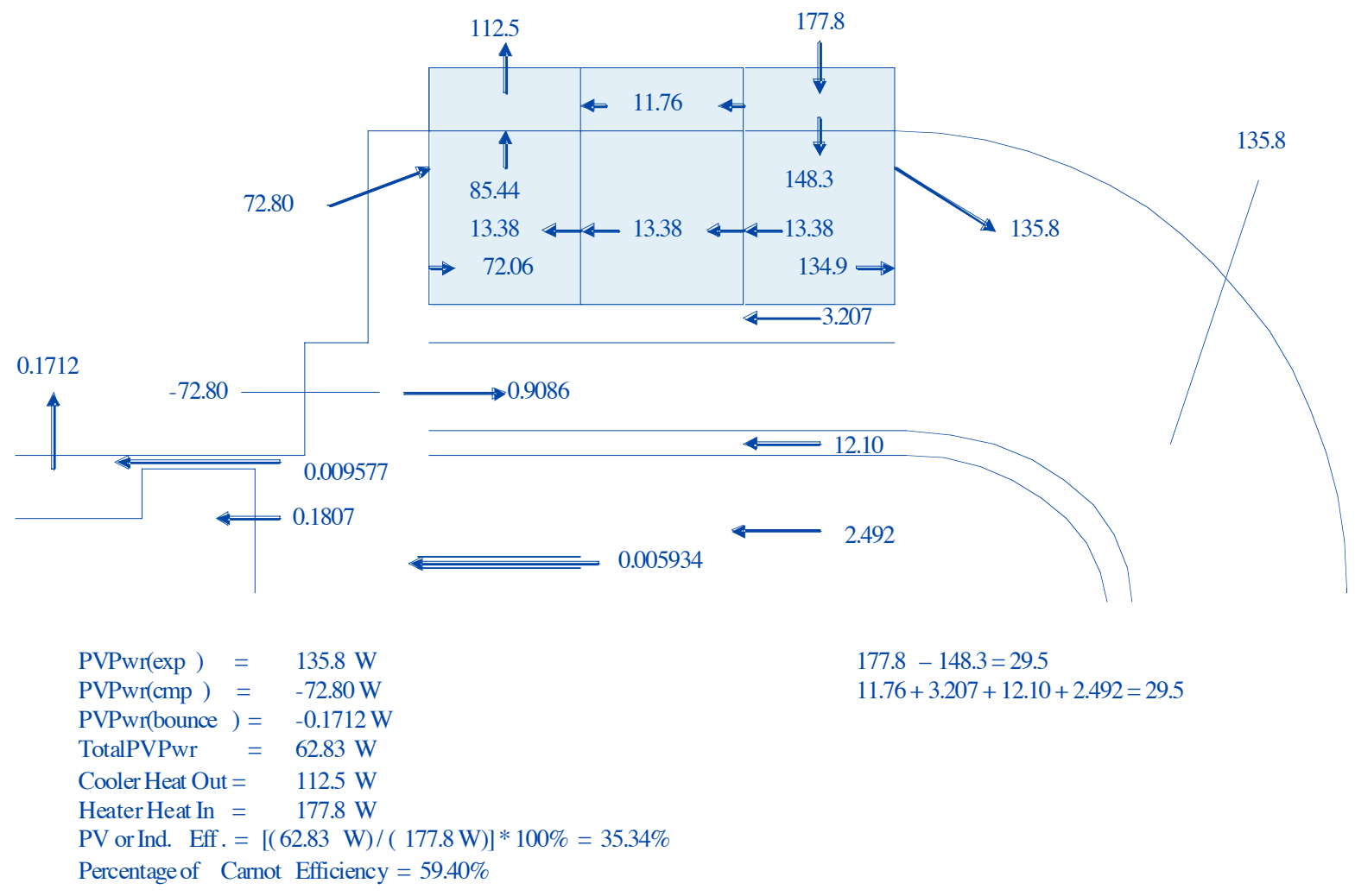

Figure 8b. Energy flow diagram for Sage Case 6 TDC model results.

Table VI. Sage Simulation Result Comparison - Case 5 and Case 6

\begin{tabular}{|l|r|r|r|r|r|r|r|}
\hline & $\begin{array}{c}\text { Heater } \\
\text { Heat } \\
\text { In (W) }\end{array}$ & $\begin{array}{c}\text { Cooler } \\
\text { Heat } \\
\text { Out } \\
\text { (W) }\end{array}$ & $\begin{array}{c}\text { Exp.Space } \\
\text { PVPwr } \\
\text { (W) }\end{array}$ & $\begin{array}{c}\text { Comp.Sp.PVPwr } \\
\text { (W) }\end{array}$ & $\begin{array}{c}\text { Total } \\
\text { PVPwr } \\
\text { (W) }\end{array}$ & $\begin{array}{c}\text { Heat } \\
\text { Cond } \\
\text { Loss } \\
\text { (W) }\end{array}$ & $\begin{array}{c}\text { PV } \\
\text { Efficiency } \\
\%\end{array}$ \\
\hline $\begin{array}{l}\text { Experimental } \\
\text { Data }\end{array}$ & 184.5 & & & & 61.8 & & 33.50 \\
\hline Case 5 & 197.6 & 124.2 & 152.9 & 82.71 & 70.20 & 30.3 & 35.52 \\
\hline Case 6 & 177.6 & 112.4 & 135.4 & 72.57 & 62.68 & 29.6 & 35.29 \\
\hline
\end{tabular}

Table VI shows the decrease in Total PV Power and changes in other energy flow parameters from Case 5 to Case 6 and provides a comparison with the experimental data. The change from the constrained to the free-displacer model, and the adjustment of spring rate and damping to match TDC data caused overall Total PV Power to decrease. The primary reason for the decrease in Total PV Power came from a decrease in displacer amplitude, 
which means that a different Stirling cycle is now being modeled than had been modeled in Cases 1 through 5 . The displacer amplitude in the Sage free-displacer model was determined by parametrically altering the spring rate and damping coefficient, with the selected combination of these constants resulting in the displacer amplitude being $14.4 \%$ less than the measured amplitude and the phase angle being different than in the data. The pressure phase angle was reduced by $0.13^{\circ}$ relative to Case 5. Compared with the TDC data, Case 6 Total PV Power was high by $0.88 \mathrm{~W}(1.4 \mathrm{~W})$ and PV Efficiency was high by 1.79 percentage points, which were the primary drivers for determining the spring rate and the damping. As stated earlier, this study will continue in the future.

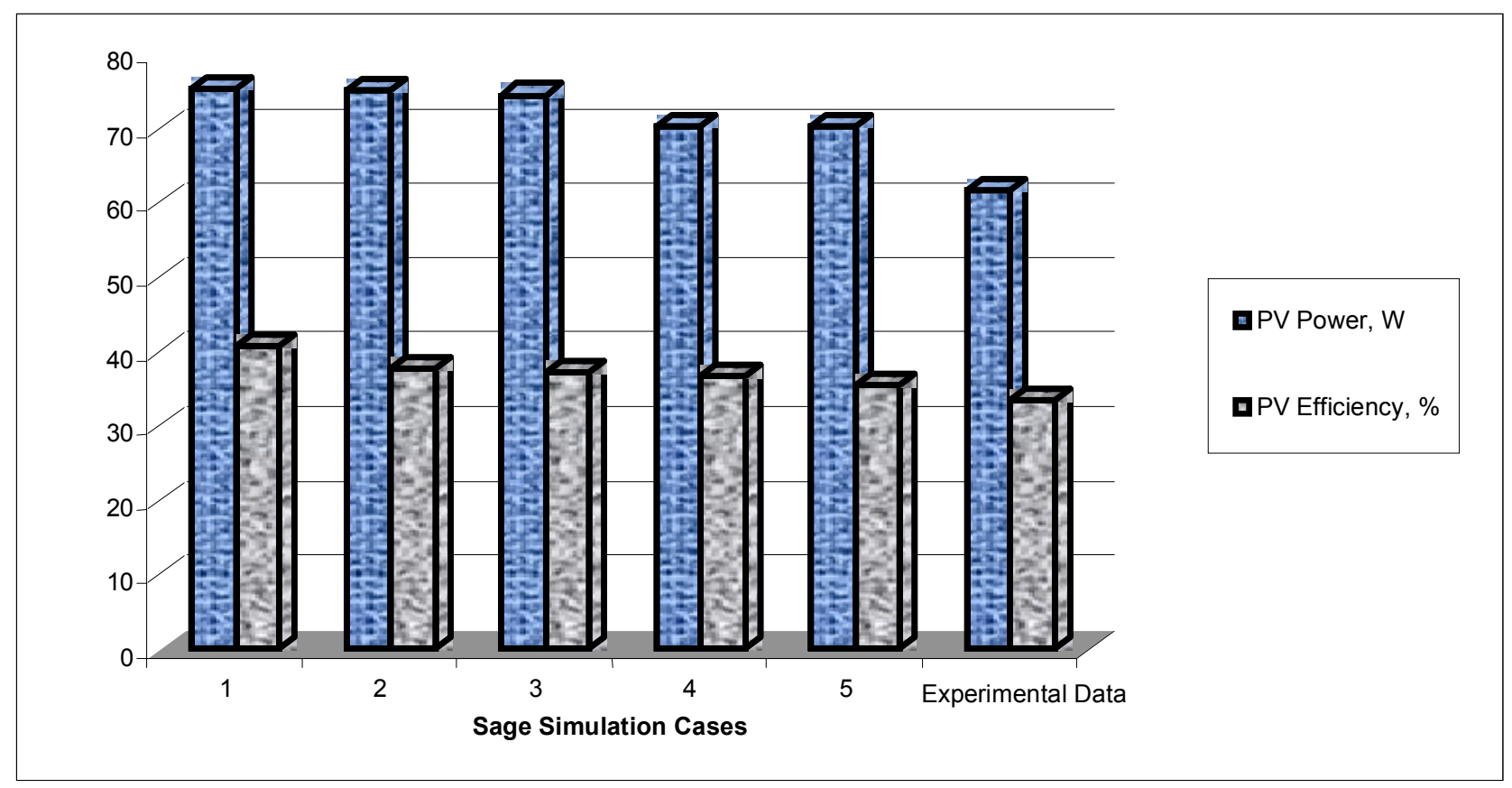

Figure 9. Sage simulation performance comparison for five cases compared with experimental data.

Fig. 9 shows the decreases of Total PV Power and PV Efficiency as the model became more refined. The decrease of the power output was caused by the increase of losses implemented in the model. The PV Efficiency also decreased as the model construction progressed.

\section{Sensitivity Check}

Initial comparisons with experimental test data suggested that some adjustments to calibration parameters provided by Sage might be valuable for code validation purposes. Therefore a sensitivity study was conducted for the Sage calibration parameters. Also, sensitivities to parameters that may have some significant uncertainty were checked. The sensitivity of the TDC model performance to heater and cooler heat transfer coefficient multipliers and regenerator friction-factor multiplier was checked. Sensitivities of model to regenerator porosity and displacer appendix gap was also checked. For these sensitivity checks, the more simple Stirling model of Case 2 was used.

\section{A. Heater / Cooler Heat Transfer Multiplier (Hmult)}

The heat transfer multipliers in Sage are empirical parameters which can be used to adjust the heat-exchanger heat-transfer correlations for code calibration purposes. These parameters, named Hmult might be expected to be 
less than 1.0, due to fin effectiveness of the heater and cooler fins. An Hmult of zero would imply no heat transfer between the solid heat exchanger and the working fluid. Hmult of 1.0 indicates a fin effectiveness of 1.0, and values greater than 1.0 might be expected if the correlations within Sage were in error. Hmult was exercised over a wider range of values than might be expected in a high performance Stirling design to see the impact.

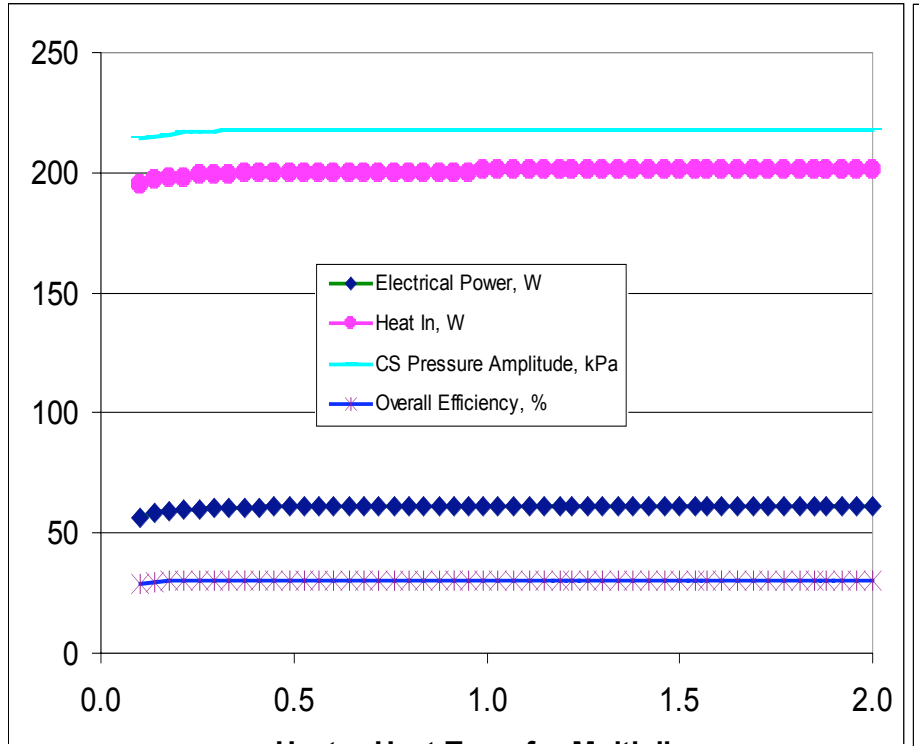

Figure 10. Electrical Power, Heat In, CS Pressure Amplitude, and Overall Efficiency as a functions of heater heat transfer multiplier.

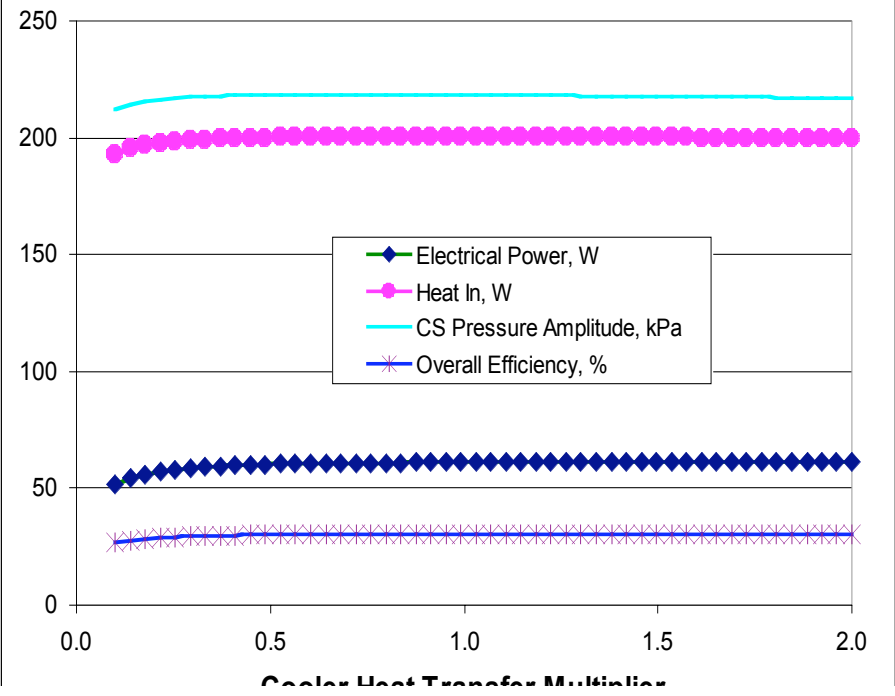

Figure 11. Electrical Power, Heat In, CS Pressure Amplitude, and Overall Efficiency as a functions of cooler heat transfer multiplier.

Figures 10 and 11 show a summary of the results as the multipliers were varied for the heater and the cooler respectively. The heat transfer multipliers of the heater and the cooler affect the performance most at values less than 1.0. At values greater than 1.0, the effect on the performance reaches a plateau, indicating that near isothermal performance of the heat exchangers has been achieved. However, reduction in Hmult below 1.0, even to values as small as 0.5 showed little effect on performance. Substantial reductions in Hmult, to values less than 0.25 were required before performance dropped noticeably.

\section{B. Regenerator Friction-Factor Multiplier (Fmult)}

The regenerator friction factor multiplier, Fmult, is a dimensionless, empirical multiplier for viscous pressure drop. Fig. 12 shows a decrease in electrical power as Fmult was increased. The decrease of electrical power is reasonable due to dissipation in the increased viscous losses. The pressure phase angle (not shown in Fig. 12) was not reduced as rapidly as the electrical power. It is worth noting that the pressure amplitude increased as the friction multiplier was increased. This seems reasonable since the power piston could "see" a greatly increased regenerator flow resistance as having a similar effect as a decrease in working space volume. Since the Case 2 model was a constrained mode model, the piston and displacer amplitudes were fixed for these sensitivity studies.

The friction factor multiplier could also be investigated in the study of a free displacer. Since the flow loss through the heat exchangers is the major source of damping on the displacer, a value of Fmult should be able to be determined through Sage that results in the correct displacer dynamics, as measured in the experimental test data. For a given design, this could provide an indication if Sage under-predicts or over-predicts flow losses. Studying the dynamics could be more telling than the PV power produced since the power dissipated through flow losses is small compared to the Total PV Power generated, yet slight changes in the flow losses will have a pronounced effect on the dynamics of the displacer. 

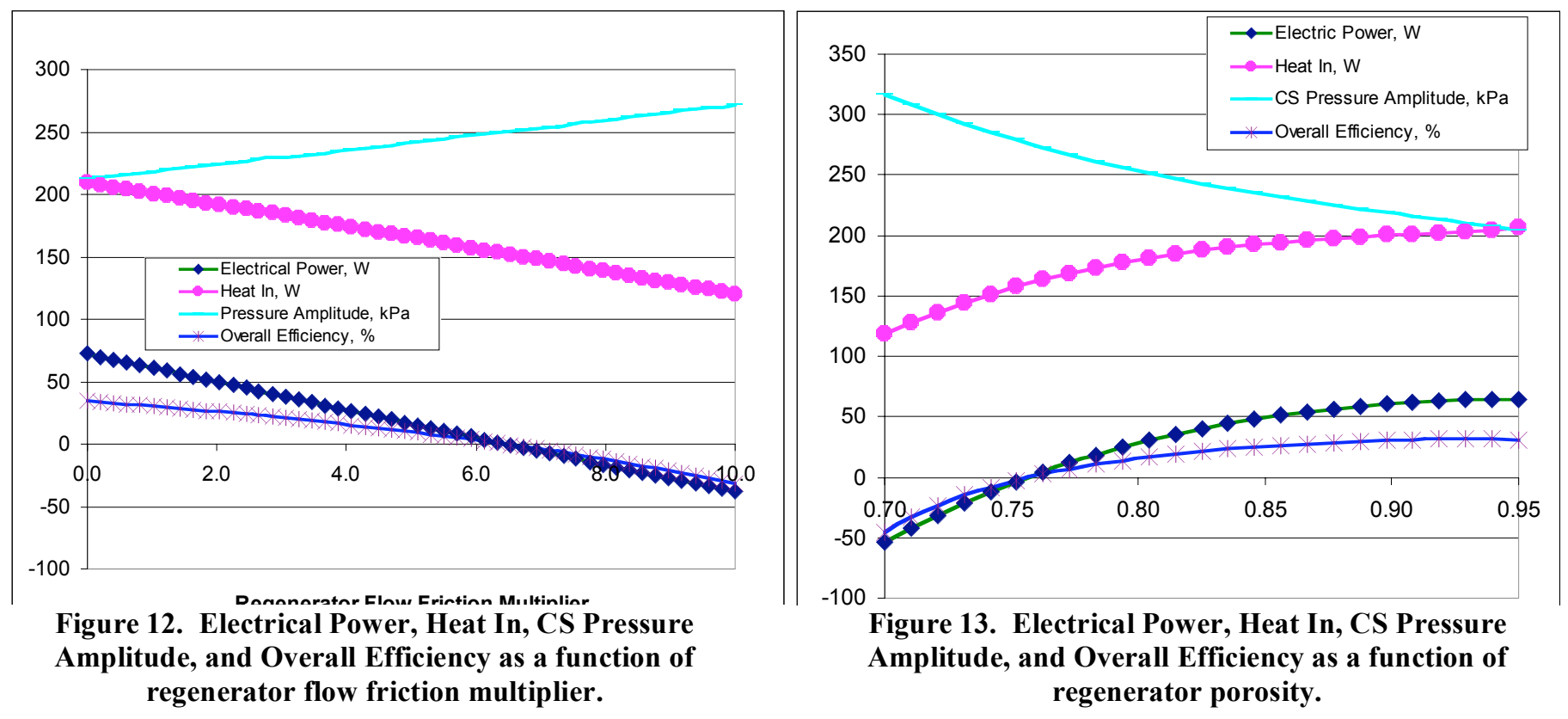

\section{Regenerator Porosity}

Fig. 13 shows the performance change as the regenerator porosity was varied. This was studied since there could be some error in measuring regenerator porosity, and with the nature of random fiber regenerators there could be some variability in the regenerator performance as a function of porosity. It was found that the cycle does not produce positive power output with the regenerator porosity less than $75 \%$, and as the porosity was increased up to 95\%, Electrical Power Output increased. The pressure phase angle (not shown in Fig. 13) increased slightly as the porosity increased, and the pressure amplitude was found to decrease. The Electric Power Output and Overall Efficiency reached a peak around $91 \%$ porosity, and then show little change up to $95 \%$ porosity. Compression space pressure amplitude and heat input both showed more sensitivity to porosity in the 90 to $95 \%$ range, than the power and efficiency.

\section{Displacer Appendix Gap}

The performance change due to the variation in the displacer appendix gap was investigated. As anticipated, increasing the size of the gap decreased the cycle efficiency, as shown in Fig. 14. This is due to increased thermal losses from the hot end to the cold end without useful thermodynamic work having been performed in the cycle by some of the working fluid. This results in increased heat input being required and decreased power output. 


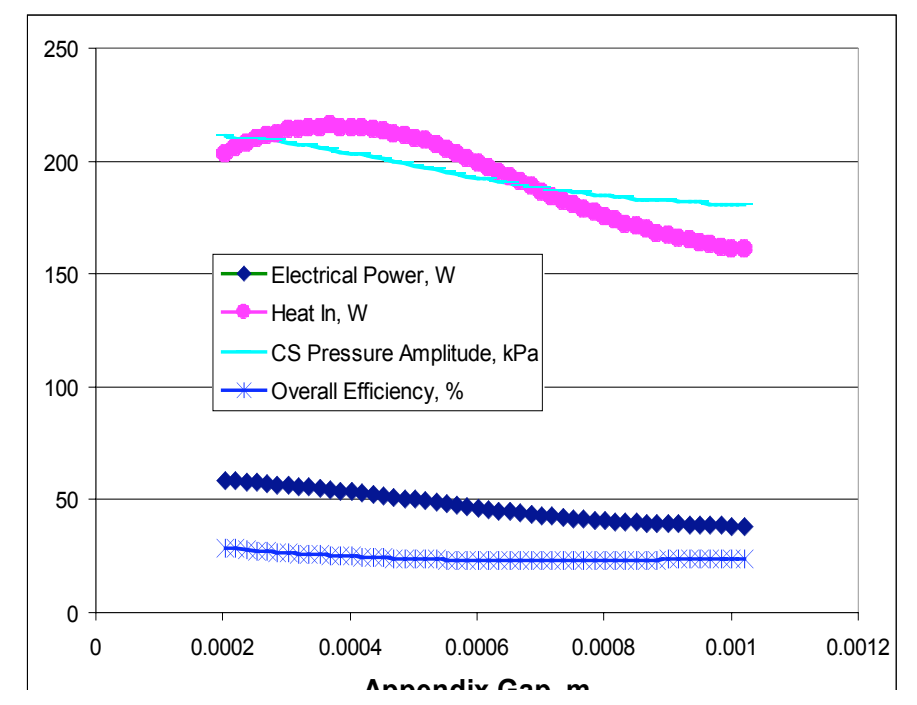

Figure 14. Electrical Power, Heat In, CS Pressure Amplitude and Overall Efficiency as a function of displacer appendix gap.

\section{Comparison of the Simulation and Experimental Results}

Simulation results were compared with an experimental data point as discussed below. Table VII shows the simulation results based on Case 5. Simulation 1 will be used as the reference, with cooler and heater Hmults and regenerator Fmult all equal to 1.0. Electric power, pressure amplitude, pressure phase angle and net efficiency were all greater than the measured experimental data. The difference between the simulated results and experimental data for electric output power was $6.86 \mathrm{~W}(13.53 \%)$, pressure amplitude was $0.029 \mathrm{MPa}(16.11 \%)$, pressure phase angle difference was $5.03^{\circ}$, and net efficiency was 1.63 percentage points $(5.93 \%)$.

Table VII. The Comparison of the Sage Simulation Result and Experimental Result Sage Constrained Displacer Model, Case 5

\begin{tabular}{|c|c|c|c|c|c|c|c|c|c|c|c|c|}
\hline $\begin{array}{l}\text { Data Point / } \\
\text { Simulation } \\
\text { Results }\end{array}$ & $\begin{array}{c}\text { Experimental Data } \\
\text { Point Time }\end{array}$ & $\begin{array}{l}\text { Fmult } \\
\text { (Regen) }\end{array}$ & $\begin{array}{l}\text { Hmult } \\
\text { (Cooler) }\end{array}$ & $\begin{array}{l}\text { Hmult } \\
\text { (Heater) }\end{array}$ & \begin{tabular}{c}
\multicolumn{2}{c}{ Net Heat } \\
Input $\quad$ (W)
\end{tabular} & \begin{tabular}{|c|} 
Difference \\
with \\
Exp. Data \\
$(\%)$ \\
\end{tabular} & $\begin{array}{l}\text { AC Power } \\
\text { Out } \quad \text { (W) }\end{array}$ & $\begin{array}{c}\text { Difference } \\
\text { with } \\
\text { Exp. Data } \\
(\%) \\
\end{array}$ & $\begin{array}{c}\text { Pressure } \\
\text { Amplitude } \\
(\mathrm{MPa})\end{array}$ & \begin{tabular}{|c} 
Difference \\
with \\
Exp. Data \\
$(\%)$
\end{tabular} & $\begin{array}{c}\text { Net } \\
\text { Efficiency } \\
(\%) \\
\end{array}$ & \begin{tabular}{|c} 
Difference \\
with \\
Exp. Data \\
$(\%)$ \\
\end{tabular} \\
\hline Experiment 2 & $\begin{array}{r}11 / 22 / 2002 \\
11: 25: 51 \\
\end{array}$ & & & & 184.5 & & 50.7 & & 0.180 & & 27.5 & \\
\hline Simulation 1 & & 1 & 1 & 1 & 197.6 & 7.10 & 57.6 & 13.5 & 0.209 & 16.1 & 29.1 & 5.93 \\
\hline Simulation 2 & & 1 & 0.5 & 0.5 & 196.7 & 6.61 & 56.6 & 11.6 & 0.209 & 16.1 & 28.8 & 4.73 \\
\hline Simulation 3 & & 1.4 & 0.5 & 0.5 & 194.1 & 5.20 & 52.5 & 3.6 & 0.211 & 17.2 & 27.1 & -1.45 \\
\hline
\end{tabular}

Simulation 2, shown in Table VII was based on improving agreement with the experimental data by adjusting the heater and cooler Hmult values with the regenerator Fmult remaining at 1.0. Improved agreement was found with values of 0.5 for both the heater and cooler, suggesting the possibility that fin effectiveness may be about 0.5 . Simulation 2 results, shown in Table VII, were all greater than the experimental data: for electric power output the 
difference was $5.93 \mathrm{~W}(11.6 \%)$, CS pressure amplitude $0.029 \mathrm{MPa}(16.1 \%)$, pressure phase angle difference was $4.6^{\circ}$, and net efficiency 1.3 percentage points $(4.7 \%)$. These differences with the experimental data are smaller than for Simulation 1.

For Simulation 3, improved agreement was found with Hmult for the heater and cooler remaining at 0.5, and regenerator Fmult changed to 1.4. The Simulation 3 results, shown in Table VII, were again greater than the measured values, but by reduced amounts. All were greater than the measured experimental data, with the exception of net efficiency which was smaller than the measured value. The differences were: electric power output difference was $1.8 \mathrm{~W}(3.6 \%)$, CS pressure amplitude $0.031 \mathrm{MPa}(17.2 \%)$, pressure phase angle difference was $4.2^{\circ}$, and net efficiency -0.4 percentage points $(-1.45 \%)$. The difference from the experimental data was smallest with this simulation result, and overall agreement of predicted and measured power and efficiency was good however, agreement of the predicted pressure amplitude and pressure phase angle with the measured experimental data values was not felt to be satisfactory. Although the end-result power and efficiency were in good agreement with the measured test data, it was apparent that there were compensating errors is some parameters used to calculate overall performance.

For future improvement of the model, a change in the radial gap between the power piston and the cylinder will be investigated. All of the clearance seals were modeled with the nominal component diameter centered in the nominal bore, with equal radial clearance seal gap around the leak path. The components should be modeled with some eccentricity, as would be expected in assembled hardware. Also, there could be some enhanced leakage or pumping effect as the piston may not operate with constant eccentricity over the entire cycle. A preliminary investigation has been conducted and the difference in the radial gap did affect the pressure phase angle.

\section{Concluding Remarks}

A Sage TDC model was developed using a step-by-step method. The changes in energy flow due to various changes in the model were documented. Sensitivities of the TDC model performance to calibration factors and to other parameters that may have some uncertainty were checked. Calibration of the constrained piston and displacer model with heater and cooler heat transfer, and regenerator friction-factor calibration factors yielded reasonable agreement with the overall engine data: predicted electric power was high by $1.8 \mathrm{~W}(3.6 \%)$; predicted heat input was high by $9.6 \mathrm{~W}$ (5.2\%); this resulted in a predicted net efficiency that was low by 0.4 percentage points (-1.6\%). While these gross results of electric power output and efficiency are in good agreement with experimental data, it is recognized that they result with pressure amplitude and pressure phase angle not in good agreement with the data. It therefore appears that there are compensating errors within the present model that allow it to generate the reasonably correct gross values. Several possible solutions are being explored to produce improved agreement with the test data by determining the correct values of the calibration factors and more accurately modeling the hardware as it exists during operation.

\section{Acknowledgments}

The work described in this paper was performed for the Science Mission Directorate (SMD) and the Radioisotope Power System (RPS) Program, which provided funding for this project. Any opinions, findings, and conclusions or recommendations expressed in this report, are those of the authors and do not necessarily reflect the views of the National Aeronautics and Space Administration.

\section{References}

${ }^{1}$ Sage, Stirling-Cycle Model, Software Package, Ver. 3.81, Gedeon Associates, Athens, OH, 2004.

${ }^{2}$ Ernst, William, et. al., "Automotive Stirling Engine Development Project Final Report”, NASA CR 190780, 1993.

${ }^{3}$ Tew, Roy; Jefferies, Kent; and Miao, David; "A Stirling Engine Computer Model For Performance Calculations," DOE/NASA/1011-78/24, NASA TM-78884, 1978.

${ }^{4}$ Tew, Roy C., Jr., "Computer Program for Stirling Engine Performance Calculations," DOE/NASA/51040-42, NASA TM$82960,1983$.

${ }^{5}$ Geng, Steven M., and Tew, Roy C., "Comparison of GLIMPS and HFAST Stirling Engine Code Predictions With Experimental Data," NASA TM 105549, 1992.

${ }^{6}$ HFAST Ver. 2.00, Mechanical Technology Inc., Latham, New York, 1993.

${ }^{7}$ Tew, Roy, "Two-Dimensional Compressible Non-Acoustic Modeling of Stirling Machine Type Components", Doctoral Dissertation, Engineering Dept., Cleveland State Univ., Cleveland, OH, 2000.

${ }^{8}$ Zhang, Zhiguo, "2D Numerical Model of Flow and Heat Transfer for Stirling Engine Components," Doctoral Dissertation, Mechanical Engineering Dept., Cleveland State University, Cleveland, OH, 2003.. 
${ }^{9}$ Tew, Roy C., Dyson, Rodger W., "Overview 2004 of NASA-Stirling Convertor CFD Model Development and Regenerator R \& D Efforts", NASA/TM-2004-213404.

${ }^{10}$ Dyson, R.W., Wilson, S.D., Tew, R.C., Demko, R., "Stirling Analysis comparison of Commercial vs. High-Order Methods", Third IECEC Conference, San Francisco, Aug. 2005.

${ }^{11}$ Dyson, R.W., Wilson, S.D., Tew, R.C., Demko, R., "Fast Whole-Engine Stirling Analysis", Third IECEC Conference, San Francisco, Aug. 2005.

${ }^{12}$ Dyson, R.W., Wilson, S.D., Tew, R.C., Demko, R., “On the Need for Multidimensional Stirling Simulations”, Third IECEC Conference, San Francisco, Aug. 2005.

${ }^{13}$ Ebiana, Asuquo, B., and Pawar, Rahul, M., et. al., "An Off-Design Sage Thermodynamic Model Of A Scaled Stirling Engine," $1^{\text {st }}$ International Energy Conversion Engineering Conference, Portsmouth, Virginia, 2003 